\title{
Supply Chain Controlling - Netzwerke steuern
}

Die Größe eines Wortes stellt die relative Häufigkeit in allen Beiträgen der Rubrik Schwerpunkt dar.

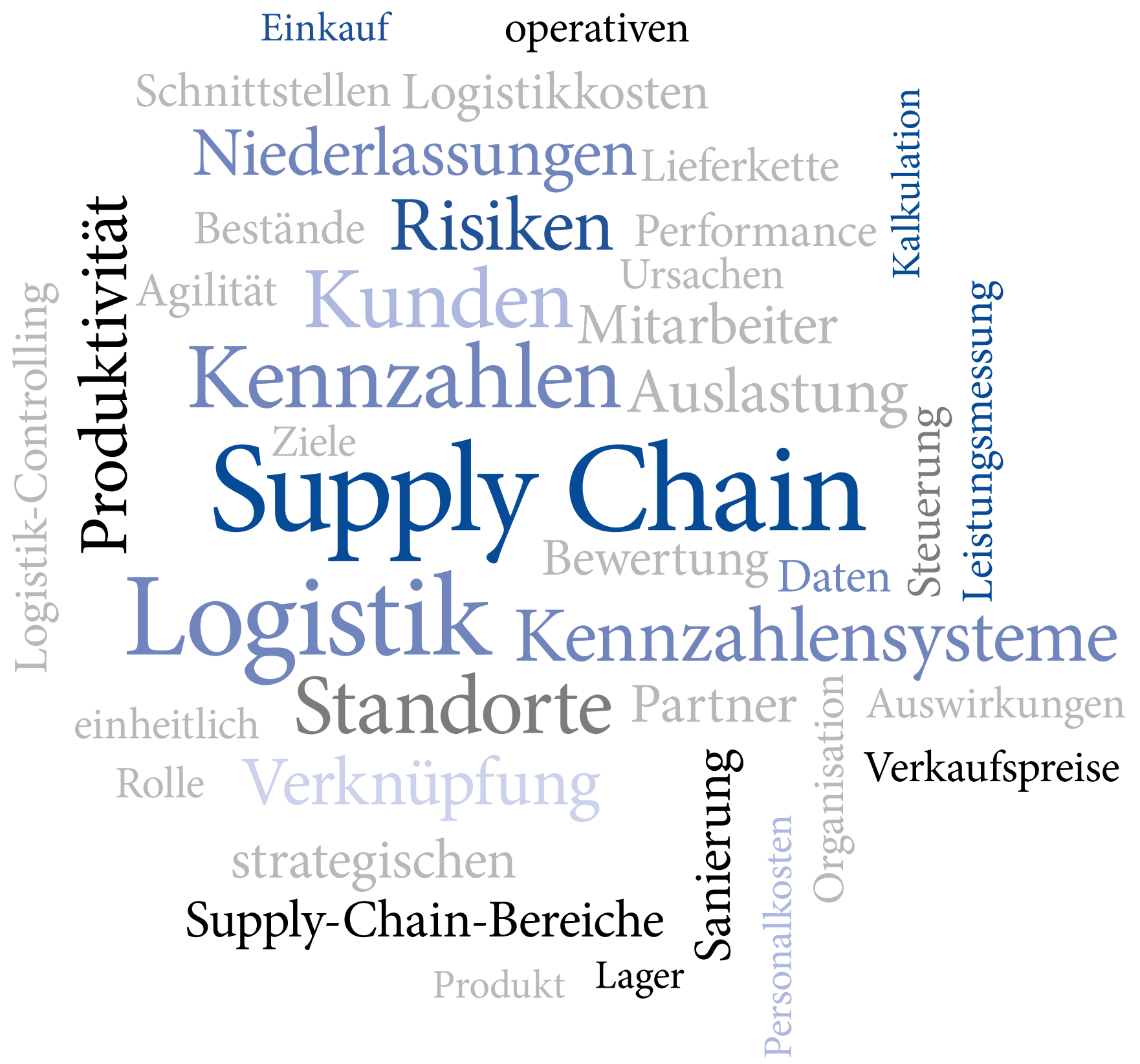

